\title{
Kontrol Relay dan Kecepatan Kipas Angin Direct Current (DC) dengan Sensor Suhu LM35 Berbasis Internet of Things (IoT)
}

\author{
Almira Budiyanto ${ }^{1}$, Genta Bayu Pramudita ${ }^{2}$, Sisdarmanto Adinandra ${ }^{3}$ \\ 1,2,3Program Studi Teknik Elektro, \\ Fakultas Teknologi Industri, \\ Universitas Islam Indonesia, Yogyakarta \\ 12almira.budiyanto@uii.ac.id, ${ }^{2} 15524014 @$ students.uii.ac.id, ${ }^{3}$ s.adinandra@uii.ac.id
}

\begin{abstract}
Abstrak
Dewasa ini masyarakat banyak tertarik dengan hal-hal yang instan dan efisien. Selain itu angka mobilitas yang tinggi menjadi salah satu faktor mengapa hal-hal yang bersifat instan dan efisien menjadi pilihan yang banyak digemari oleh masyarakat. Menjawab tantangan ini Internet of Things (IoT) hadir untuk membantu masyarakat dengan cara mengkoneksikan berbagai objek ke jaringan internet yang kemudian dapat diakses dari mana saja. Penelitian ini bertujuan untuk mengetahui kinerja sistem IoT dengan platform aplikasi Blynk pada smartphone android. Metode yang digunakan adalah penggunaan sensor suhu LM35 sebagai input suhu. Pada perancangan ini menggunakan motor Direct Current (DC) yang dapat diatur dengan metode Pulse Width Modulation (PWM) dan dikendalikan melalui aplikasi Blynk pada smartphone android. Sensor suhu LM35 memiliki batasan suhu $27^{\circ} \mathrm{C}$ sampai $40^{\circ} \mathrm{C}$ yang menghasilkan kenaikan rata-rata $\mathrm{PWM}$ sebesar $6,3 /{ }^{\circ} \mathrm{C}$ dan putaran motornya bertambah sebesar $244 \mathrm{rpm} /{ }^{\circ} \mathrm{C}$. Perancangan ini ditambahkan motor servo dan relay yang dapat dikendalikan dengan aplikasi Blynk pada smartphone android.
\end{abstract}

Kata kunci: Internet of Things (IoT), Android, Blynk, relay, kipas angin

\begin{abstract}
People nowadays concern to instant and efficient things due to their high mobility. In order to face this challenge, Internet of Things (IOT) become a popular choice to interconnect several objects through internet and also accessible from everywhere. This study aims to investigate the IoT performance with Blynk platform on a Android smartphone. The proposed methods used Pulse Width Modulation (PWM) controlled DC motor and Blynk application run on Android smartphone. The temperature sensor LM35 has range of $27^{\circ} \mathrm{C}$ to $40^{\circ} \mathrm{C}$ and yields average increment of $\mathrm{PWM}$ and motor speed of 6.3 per ${ }^{\circ} \mathrm{C}$ and $244 \mathrm{rpm} /{ }^{\circ} \mathrm{C}$, respectively. The realization is augmented with servomotor and relay which are remotely controlled using Blynk application on Android smartphone.
\end{abstract}

Keywords: Internet of Things (IoT), Android, Blynk, relay, fan

\section{Pendahuluan}

Dewasa ini orang-orang sangat gemar dengan hal yang instan, mudah, serba otomatis, fleksibel dan efisien. Terlebih sebagai milenial, kegiatan mulai dari studi, kerja hingga kegiatan di luar yang mobilitasnya sangat tinggi membutuhkan sebuah inovasi 
baru yang bermanfaat untuk mendukung produktifitas kegiatannya. Sudah menjadi wajar, karena mobilitas yang tinggi ini menyebabkan manusia kadang sering lalai dan malas karena terlalu lelah dengan kegiatan yang ada. Kebutuhan ini mendukung sebuah gagasan baru yang baru-baru ini menjadi "trend" di kalangan milenial yaitu, Internet of Things (IoT). IoT adalah salah satu wujud perkembangan teknologi terbaru di abad ini yang berkembang cukup pesat, dengan menggunakan koneksi internet yang dapat mempermudah sebagian besar aktifitas dalam kehidupan sehari hari, dan memungkinkan milenial dapat dengan mudah mendapatkan ide-ide atau pengembangan untuk membuat berbagai macam inovasi teknologi [1].

Konsep IoT yaitu bagaimana setiap objek atau benda dalam kehidupan sehari-hari dapat terkoneksi ke jaringan internet, setiap objek atau benda tersebut dapat mengirimkan data ke internet untuk kemudian dapat di akses dari mana saja dan kapan saja. Pada hal ini juga memungkinkan objek atau benda dapat terkoneksi dan berinteraksi langsung dengan benda-benda lainnya. Istilah ini juga sering dikenal dengan komunikasi Machine to Machine (M2M) [2]. Hal ini yang nantinya akan menjawab kebutuhan manusia di abad ini untuk tetap dapat melakukan aktitas dengan mobilitas tinggi tanpa takut lalai atau membuang waktu dengan mengerjakan hal yang dapat di kerjakan dimana saja dan kapan saja. Saat ini, IoT menjadi hal yang tidak dapat terpisahkan bagi masyarakat. Mulai dari membantu pekerjaan manusia sehari-hari, maupun skala industri. IoT memiliki spektrum sangat luas mencakup setiap aspek interaksi manusia dalam kehidupan sehari-hari, mulai dari membeli barang hingga perawatan kesehatan, bahkan memantau sumber daya yang dari jarak jauh. Dengan ini maka sumber daya manusia dapat dimanfaatkan secara lebih efisien [3].

Beberapa penelitian sebelumnya terkait smart home yaitu sistem kontrol motor DC yang menggunakan suhu udara sebagai pemicu dengan bantuan sensor suhu LM35 [4]. Penelitian sejenis lainnya yaitu membuat sistem kontrol rumah pintar yang dapat memfasilitasi aktifitas manusia seperti menyalakan dan mematikan lampu, membuka dan menutup pintu, mengatur suhu kamar, menjaga keamanan rumah. Sistem kontrol mikrokontroler yang digunakan adalah bluetooth sehingga jarak yang dapat menjangkau hanya maksimal 10 meter [5]. Sedangkan penelitian terkait pengaplikasian IoT yaitu sistem kontrol IoT yang berperan sebagai pengontrolan dan pemantauan. Melalui aplikasi smartphone, pengguna dapat mengontrol dan memonitoring peralatan listrik yang terhubung. Selanjutnya, sistem kontrol mekanik digunakan untuk mengontrol peralatan elektronik menggunakan saklar manual yang bertujuan jika smartphone pengguna mati atau sub-sistem IoT terjadi error maka peralatan listrik yang ada tetap bias dihidupkan maupun dimatikan [6]-[8].

Penelitian lainnya menggunakan komunikasi jarak pendek dengan komunikasi ZigBee untuk pengiriman data ke server dan modul ESP8266 sebagai web server serta bertugas untuk upload data ke server Thingspeak. Penelitian lain yaitu mengenai penggunaan software Blynk yang dapat mengontrol led, relay dan monitoring suhu serta dapat mensimulasikan program untuk pengontrolan melalui jaringan internet di android. Sistem ini terdiri dari tiga sub sistem, sub sistem yang pertama terdiri dari modul GPS untuk mendapatkan geo location, kemudian sub sistem kedua terdiri dari beberapa sensor seperti DHT11 untuk mengukur suhu, sensor PIR untuk mendeteksi gerakan dan sensor ultrasonik untuk mengukur jarak, sub sistem ketiga terdiri dari relay dan master microcontroller yang memiliki fungsi sebagai koordinator pusat yang dapat berkomunikasi dengan subsistem lain melalui Wi-Fi. Data sensor dapat dilihat dengan bantuan smartphone menggunakan resberry Pi sebagai server pribadi [9]-[11]. Aplikasi 
lain dari IoT yaitu menggunakan robot untuk mendukung keperluan smarthome. Robotrobot dikontrol sedemikian rupa sehingga mampu menyediakan layanan untuk kehidupan sehari-hari di dalam rumah. Selain itu, aplikasi dengan pengolahan citra juga cukup populer untuk mendukung sistem smarthome [12]-[14].

Untuk membantu menjawab kebutuhan masyarakat milenial, maka pada penelitian ini akan membuat sistem IoT dengan bantuan aplikasi Blynk pada Smartphone Android yang dapat mengontrol kecepatan kipas angin motor Direct Current (DC) dengan bantuan sinyal Pulse Width Modulation (PWM), dapat mengontrol motor servo dan dapat mengontrol relay yang nantinya dapat tersambung ke berbagai macam peralatan elektronik. Sehingga dengan adanya sistem IoT dapat memudahkan pengguna yang tidak perlu lagi mengontrol peralatan elektronik dengan jarak dekat. Singkatnya, dapat menghemat tenaga, waktu dan dapat dilakukan kapan dan di mana saja.

\section{Tinjauan Pustaka}

\subsection{NodeMCU ESP8266}

NodeMCU ESP8266 adalah sebuah mikrokontroler yang berupa sebuah board elektronik yang memiliki chip ESP8266 dengan kemampuan dapat menjalankan fungsi Microcontroller dan juga koneksi internet Wi-Fi. NodeMCU ESP8266 memiliki beberapa pin I/O sehingga Microcontroller ini menjadi popular untuk aplikasi monitoring maupun controlling pada proyek sistem IoT. NodeMCU dapat diprogram dengan Compillernya Arduino yaitu dengan Software Arduino IDE. NodeMCU memiliki port USB yang memudahkan dalam pemrogramannya [15]. Gambar 1 menunjukkan gambar NodeMCU ESP8266 yang digunakan pada penelitian ini.

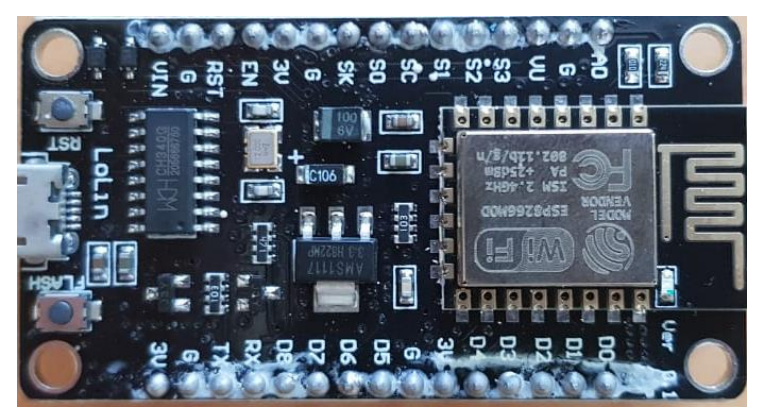

Gambar 1. NodeMCU ESP8266

\subsection{Motor DC}

Motor listrik DC merupakan suatu perangkat yang dapat mengubah energi listrik menjadi energi kinetik atau gerakan. Motor DC memiliki dua terminal dan memerlukan tegangan arus searah yaitu arus DC oleh karena itu motor DC juga sering disebut dengan motor arus searah. Motor listrik DC menghasilkan sejumlah putaran per menit atau sering disebut dengan istilah Revolution Per Minute (RPM) dan dapat diubah arah putaran searah jarum jam ataupun sebaliknya apabila polaritas listrik yang diberikan pada motor DC tersebut dibalikkan. Apabila tegangan yang diberikan kepada motor DC lebih rendah dari tegangan operasionalnya maka akan dapat memperlambat rotasi motor sedangkan tegangan yang lebih tinggi akan membuat rotasi motor DC akan semakin cepat. Pada 
perancangan ini digunakan motor DC dari kipas CPU karena memiliki dimensi yang kecil dan memiliki kapasitas $12 \mathrm{~V}$ sehingga putaran yang dihasilkan cukup cepat.

\subsection{Driver Motor}

Driver motor berfungsi sebagai pengatur arah putaran dan kecepatan putaran motor dengan metode PWM. Driver motor yang digunakan pada perancangan ini adalah sebuah rangkaian H-bridge Mosfet yang merupakan sebuah rangkaian elektronika. Rangkaian driver motor yang digunakan pada penelitian ditunjukkan oleh Gambar 2.

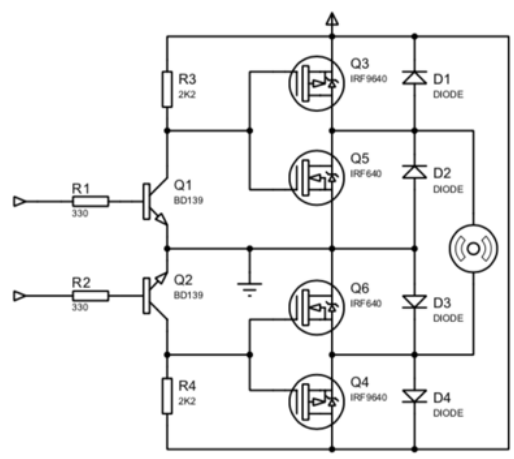

Gambar 2. Driver motor

\subsection{Motor Servo}

Motor servo merupakan sebuah perangkat atau aktuator putar yang dirancang dengan sistem kontrol umpan balik loop tertutup (servo), sehingga dapat di set-up untuk menentukan dan memastikan posisi sudut dari poros output motor. Motor Servo terdiri dari motor DC dan serangkaian Gear, rangkaian kontrol dan potensiometer. Serangkaian Gear yang melekat pada poros motor DC akan memperlambat putaran poros dan meningkatkan torsi motor Servo. Gambar 3 menunjukkan gambar motor servo.

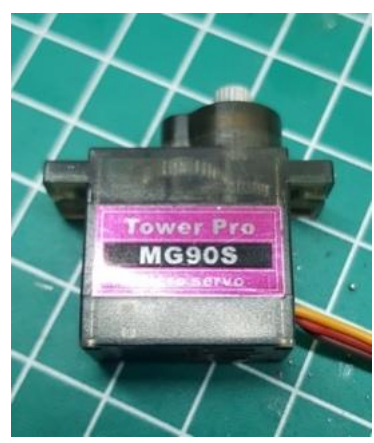

Gambar 3. Motor servo

\subsection{Modul 4 Relay}

Relay merupakan saklar (switch) yang dioperasikan melalui listrik dan merupakan komponen Elektromechanical yang mempunyai dua bagian utama yaitu elektromagnet (koil) dan mekanikal (kontak saklar switch). Prinsip yang digunakan relay yaitu elektromagnetik yang digunakan untuk menggerakan kontak saklar sehingga dengan arus listrik yang kecil (low power) akan menghantarkan listrik yang bertegangan lebih tinggi. Pada relay biasanya terdapat kumparan yang berinti besi dan bilamana kumparan tersebut terkena aliran listrik maka kumparan tersebut akan menjadi magnet dan akan menarik kontak sehingga terjadi kontak, pada saat kontak terhubung maka aliran akan 
mengalir. Pada perancangan kali ini menggunakan modul 4 relay yang bertujuan agar dapat menyambungkan 4 buah alat elektronik secara bersamaan. Gambar 4 menunjukkan module 4 relay.

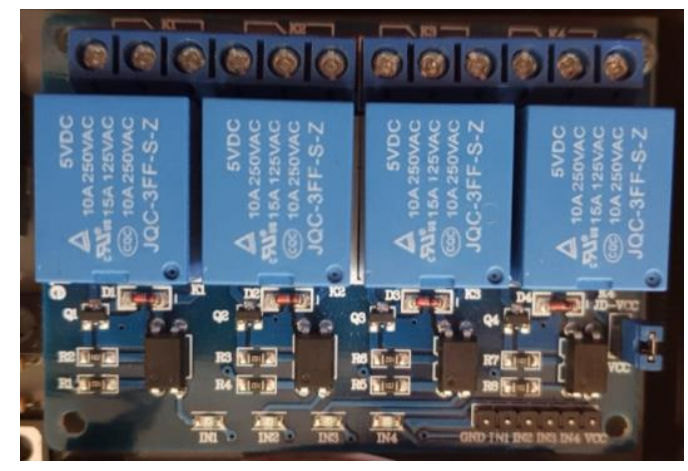

Gambar 4. Modul 4 relay

\subsection{Sensor Suhu LM35}

Sensor suhu LM35 adalah komponen elektronika yang berfungsi untuk mengubah besaran suhu menjadi besaran listrik dalam bentuk tegangan. Secara prinsip sensor akan melakukan penginderaan pada saat perubahan suhu setiap 1 derajat Celcius akan menunjukan tegangan sebesar $10 \mathrm{mV}$. Jangka sensor ini mulai dari -55 derajat Celcius sampai dengan 150 derajat Celcius. Sensor suhu LM35 yang digunakan pada penelitian ini ditunjukkan oleh Gambar 5.

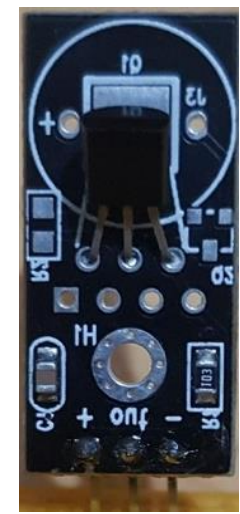

Gambar 5. Sensor Suhu LM35

\section{Metode}

Program yang digunakan adalah Arduino IDE dan aplikasi Blynk sebagai pusat kontrol pada smartphone android. Pada program Arduino IDE hal yang paling penting untuk mengkoneksikan dengan aplikasi Blynk adalah alamat pin, token yang dikirim email dari aplikasi Blynk dan alamat Wi-Fi yang dapat dijangkau NodeMCU ESP 8266. Pemrograman alamat dan port software arduino ide ditunjukkan oleh Gambar 6. 


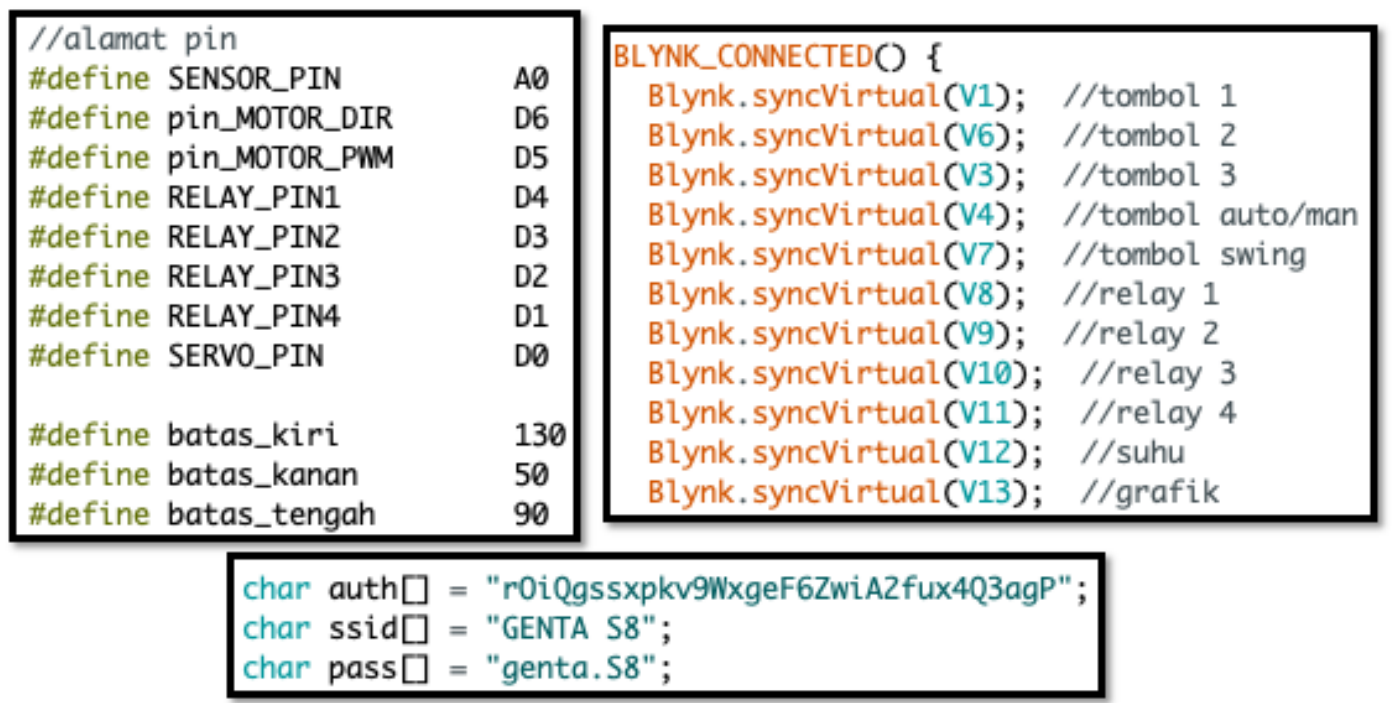

Gambar 6. Pemrograman alamat dan port software Arduino IDE

Aplikasi Blynk adalah platform IoT yang dapat diunduh gratis melalui Playstore. Tahap awal yang harus dilakukan adalah membuat akun baru dengan email yang aktif agar mendapatkan kode token. Pada aplikasi Blynk sudah tersedia model tombol yang dapat diatur alamat tombolnya seperti pada Gambar 7.
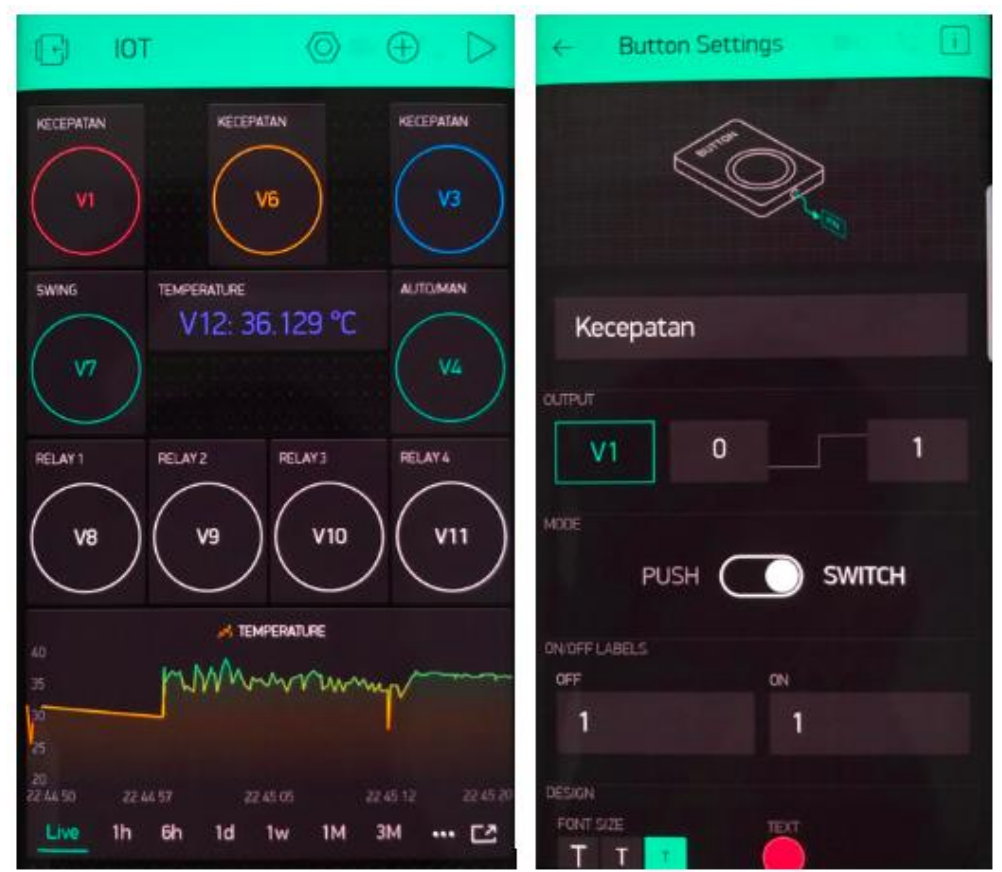

Gambar 7. Setingan aplikasi Blynk

Pada perancangan hardware diperlukan pembuatan board agar semua komponen hardware dapat terkoneksi dengan baik. Gambar 8 menunjukkan skematik rangkaian sedangkan Gambar 9 menunjukkan desain dan bentuk fisik dari board. 


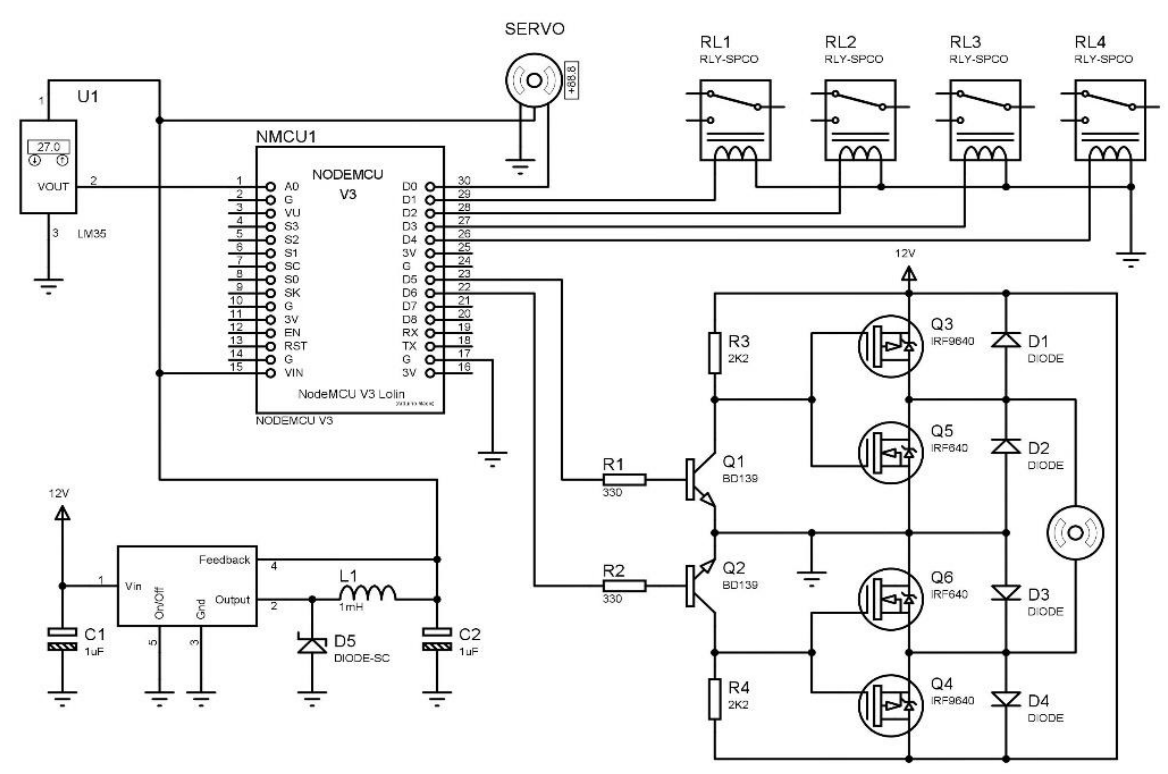

Gambar 8. Skematik rangkaian
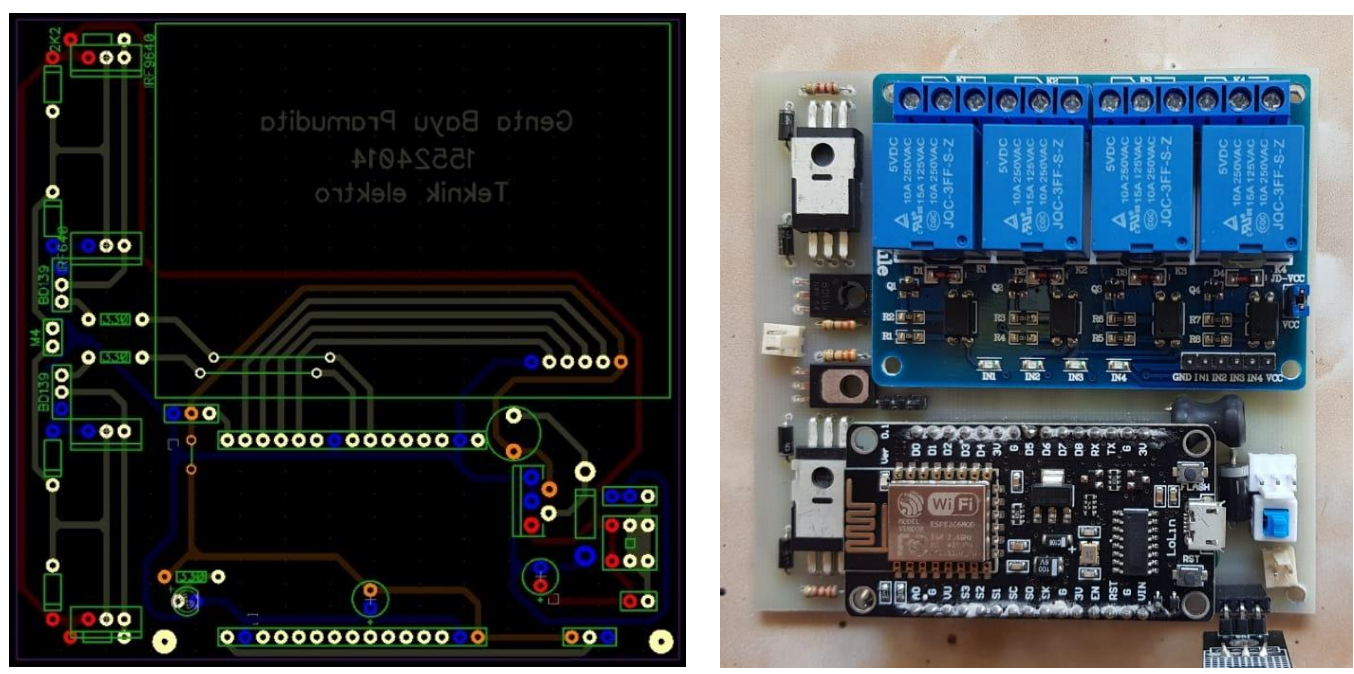

Gambar 9. Desain dan bentuk fisik board

\section{Hasil dan Pembahasan}

Beberapa hasil pengujian yang dibahas pada bab ini, yaitu:

- Kalibrasi sensor suhu LM35

- Pengujian kecepatan motor DC terhadap suhu ruangan dengan mode otomatis

- Pengujian perpindahan kecepatan motor DC dengan mode manual

- Pengujian motor Servo

- Pengujian kontrol Relay 
Techné: Jurnal Ilmiah Elektroteknika Vol. 19 No. 01 April 2020 Hal 43 - 54

\subsection{Pengujian kalibrasi sensor suhu LM35}

Tabel 1 merupakan hasil kalibrasi sensor LM35 terhadap Envirometer sebagai pembanding. Pada percobaan kalibrasi ini didapat hasil presentase error sebesar 1,05\%. Pada Tabel 1 juga dapat dilihat ketika suhu $39,6^{\circ} \mathrm{C}$ memiliki kesamaan pembacaan sensor suhu LM35 dengan suhu pada Envirometer dan pada suhu $40,3^{\circ} \mathrm{C}$ memiliki selisih yang paling banyak yaitu sebesar $0,7^{\circ} \mathrm{C}$. Error terbesar terjadi pada saat LM35 menunjukkan $28,1^{\circ} \mathrm{C}$ sedangkan pengujian pada environmeter adalah $28,7^{\circ} \mathrm{C}$ perbedaan ini menghasilkan error hingga $2,1 \%$.

Tabel 1. Kalibrasi sensor LM35

\begin{tabular}{|c|c|c|c|}
\hline $\begin{array}{c}\text { Pengujian pada } \\
\text { sensor LM35 }\end{array}$ & $\begin{array}{c}\text { Pengujian pada } \\
\text { Envirometer }\end{array}$ & Perbedaan suhu & \% error \\
\hline $27,3^{\circ} \mathrm{C}$ & $27,8^{\circ} \mathrm{C}$ & $0,5^{\circ} \mathrm{C}$ & 1,8 \\
\hline $28,1^{\circ} \mathrm{C}$ & $28,7^{\circ} \mathrm{C}$ & $0,6^{\circ} \mathrm{C}$ & 2,1 \\
\hline $29,4^{\circ} \mathrm{C}$ & $29,5^{\circ} \mathrm{C}$ & $0,1^{\circ} \mathrm{C}$ & 0,3 \\
\hline $30,9^{\circ} \mathrm{C}$ & $30,3^{\circ} \mathrm{C}$ & $0,6^{\circ} \mathrm{C}$ & 1,9 \\
\hline $31,2^{\circ} \mathrm{C}$ & $31,7^{\circ} \mathrm{C}$ & $0,5^{\circ} \mathrm{C}$ & 1,5 \\
\hline $32,3^{\circ} \mathrm{C}$ & $32,6^{\circ} \mathrm{C}$ & $0,3^{\circ} \mathrm{C}$ & 0,9 \\
\hline $33,4^{\circ} \mathrm{C}$ & $33,1^{\circ} \mathrm{C}$ & $0,1^{\circ} \mathrm{C}$ & 0,3 \\
\hline $34,4^{\circ} \mathrm{C}$ & $34,2^{\circ} \mathrm{C}$ & $0,2^{\circ} \mathrm{C}$ & 0,6 \\
\hline $35,3^{\circ} \mathrm{C}$ & $35,8^{\circ} \mathrm{C}$ & $0,5^{\circ} \mathrm{C}$ & 1,4 \\
\hline $36,7^{\circ} \mathrm{C}$ & $36,4^{\circ} \mathrm{C}$ & $0,3^{\circ} \mathrm{C}$ & 0,8 \\
\hline $37,8^{\circ} \mathrm{C}$ & $37,4^{\circ} \mathrm{C}$ & $0,4^{\circ} \mathrm{C}$ & 1,1 \\
\hline $38,1^{\circ} \mathrm{C}$ & $38,6^{\circ} \mathrm{C}$ & $0,5^{\circ} \mathrm{C}$ & 1,3 \\
\hline $39,6^{\circ} \mathrm{C}$ & $39,6^{\circ} \mathrm{C}$ & $0^{\circ} \mathrm{C}$ & 0 \\
\hline $40,3^{\circ} \mathrm{C}$ & $40,6^{\circ} \mathrm{C}$ & $0,7^{\circ} \mathrm{C}$ & 0,7 \\
\hline & Rata-rata $\%$ error & & 1,05 \\
\hline
\end{tabular}

\subsection{Pengujian Kecepatan Motor Terhadap Suhu Ruangan dengan Mode Otomatis.}

Pada Tabel 2 dapat dilihat bahwa kenaikan suhu yang terjadi akan mengakibatkan PWM ikut menjadi bertambah, rata-rata pertambahan PWM sebesar 6,3 poin. Hal ini terjadi karena pengaruh ketetapan batas maksimal suhu sebesar $40^{\circ} \mathrm{C}$ yang artinya pada suhu $40^{\circ} \mathrm{C}$ PWM yang dihasilkan juga maksimal sebesar 255. Dapat dilihat juga pada pengukuran RPM menunjukan bahwa putaran motor menjadi bertambah cepat dengan rata rata kenaikan 244 RPM setiap kenaikan satu derajat suhu.

Tabel 2. Pengujian kecepatan motor dengan mode otomatis

\begin{tabular}{|c|c|c|}
\hline $\begin{array}{c}\text { Suhu yang terbaca } \\
\text { pada sensor } L M 35\end{array}$ & PWM yang dihasilkan & $\begin{array}{c}\text { Kecepatan kipas } \\
\text { (RPM) }\end{array}$ \\
\hline $27,3^{\circ} \mathrm{C}$ & 174 & 10280 \\
\hline $28,1^{\circ} \mathrm{C}$ & 179 & 10700 \\
\hline $29,4^{\circ} \mathrm{C}$ & 187 & 10900 \\
\hline $30,9^{\circ} \mathrm{C}$ & 197 & 11317 \\
\hline $31,2^{\circ} \mathrm{C}$ & 198 & 11400 \\
\hline $32,3^{\circ} \mathrm{C}$ & 205 & 11600 \\
\hline $33,4^{\circ} \mathrm{C}$ & 212 & 12100 \\
\hline $34,4^{\circ} \mathrm{C}$ & 219 & 12400 \\
\hline $35,3^{\circ} \mathrm{C}$ & 225 & 12500 \\
\hline $36,7^{\circ} \mathrm{C}$ & 233 & \\
\hline
\end{tabular}




\begin{tabular}{|c|c|c|}
\hline $\begin{array}{c}\text { Suhu yang terbaca } \\
\text { pada sensor } L M 35\end{array}$ & PWM yang dihasilkan & $\begin{array}{c}\text { Kecepatan kipas } \\
\text { (RPM) }\end{array}$ \\
\hline $37,8^{\circ} \mathrm{C}$ & 241 & 12700 \\
\hline $38,1^{\circ} \mathrm{C}$ & 242 & 12800 \\
\hline $39,6^{\circ} \mathrm{C}$ & 252 & 13022 \\
\hline $40,3^{\circ} \mathrm{C}$ & 255 & 13458 \\
\hline
\end{tabular}

Gambar 10 (a) menunjukan bahwa perbandingan PWM terhadap suhu berbanding lurus. Pada saat suhu semakin tinggi maka nilai PWM akan menjadi lebih besar. Hal ini juga dibuktikan pada Gambar 10 (b) yang menunjukan nilai RPM kipas angin motor DC semakin besar saat suhu bertambah tinggi. Pengujian ini sesuai teori karena kipas angin motor DC dapat bertambah cepat seiring dengan suhu yang semakin panas. Pada saat suhu $27^{\circ} \mathrm{C}$ memiliki nilai PWM sebesar 174 dari rentang $0-255$, dan pada suhu $40^{\circ} \mathrm{C}$ memiliki nilai PWM maksimal sebesar 255 dan pada saat nilai maksimal mempunyai putaran maksimal sebesar 13458 RPM.

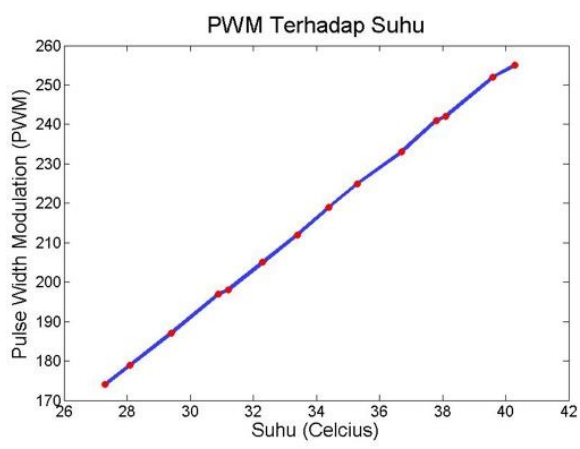

(a)

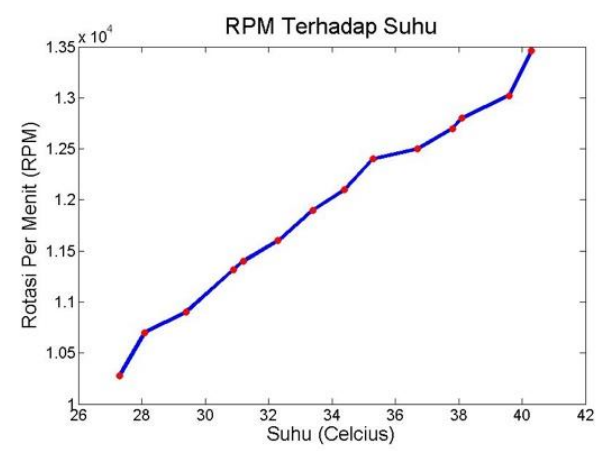

(b)

Gambar 10. Pengaruh suhu terhadap (a) PWM dan (b) RPM

\subsection{Pengujian Perpindahan Kecepatan Motor DC Dengan Mode Manual}

Pada Tabel 3 dapat dilihat bahwa hasil switch kecepatan yang dikendalikan melalui tombol pada aplikasi Blynk berjalan sesuai dengan seharusnya. Pada saat kecepatan rendah, sedang, dan maksimal berbanding lurus dengan kecepatan RPM yang dihasilkan motor DC. Pada kecepatan rendah menghasilkan RPM sebesar 8028 sedangkan pada kondisi PWM maksimal menghasilkan RPM sebesar 13280. Kecepatan kipas angin motor DC diatur dengan memberikan nilai PWM yang berbeda.

Tabel 3. Perpindahan kecepatan dengan mode manual

\begin{tabular}{|c|c|c|}
\hline Kecepatan & PWM & RPM \\
\hline 1 & 125 & 8028 \\
\hline 2 & 188 & 10700 \\
\hline 3 & 255 & 13280 \\
\hline
\end{tabular}




\subsection{Pengujian Motor Servo}

Tabel 4 menunjukkan hasil percobaan yang dilakukan pada motor servo. Motor servo diatur dengan perpindahan sudut putaran $50^{\circ}$ dan $130^{\circ}$ dengan kondisi awal $90^{\circ}$ pada posisi tengah. Percobaan ini menghasilkan perpindahan sudut motor servo dari $90^{\circ}$ menuju sudut $50^{\circ}$ sebesar $40^{\circ}$ yang diukur dengan busur derajat, sedangkan pada sudut $50^{\circ}$ menuju $130^{\circ}$ menghasilkan perpindahan sudut sebesar $80^{\circ}$ yang sesuai dengan pengukuran pada busur derajat.

Tabel 4. Pengujian motor servo

\begin{tabular}{|c|c|}
\hline Sudut putaran motor servo & Sudut pada busur derajat \\
\hline $90^{\circ}-50^{\circ}$ & $40^{\circ}$ \\
\hline $50^{\circ}-130^{\circ}$ & $80^{\circ}$ \\
\hline $90^{\circ}-130^{\circ}$ & $40^{\circ}$ \\
\hline
\end{tabular}

\subsection{Pengujian Respon Kontrol Relay}

Pada Tabel 5 pengujian kontrol relay, jarak antara smartphone sebagai pengontrol dengan NodeMCU tidak mempengaruhi respon relay. Pengujian respon relay dilakukan dengan kondisi relay tanpa dihubungkan dengan peralatan elektronik. Pengujian respon relay saat kondisi jauh menggunakan bantuan fitur video call melalui smartphone.

Tabel 5. Pengujian respon kontrol relay

\begin{tabular}{|c|c|c|c|}
\hline $\begin{array}{c}\text { Jangkauan } \\
\text { (meter) }\end{array}$ & $\begin{array}{c}\text { Respon } \\
\text { perangkat }\end{array}$ & $\begin{array}{c}\text { Jangkauan } \\
\text { (meter) }\end{array}$ & $\begin{array}{c}\text { Respon } \\
\text { perangkat }\end{array}$ \\
\hline 10 & merespon & 160 & merespon \\
\hline 20 & merespon & 170 & merespon \\
\hline 30 & merespon & 180 & merespon \\
\hline 40 & merespon & 190 & merespon \\
\hline 50 & merespon & 200 & merespon \\
\hline 60 & merespon & 210 & merespon \\
\hline 70 & merespon & 220 & merespon \\
\hline 80 & merespon & 230 & merespon \\
\hline 90 & merespon & 240 & merespon \\
\hline 100 & merespon & 250 & merespon \\
\hline 110 & merespon & 260 & merespon \\
\hline 120 & merespon & 270 & merespon \\
\hline 130 & merespon & 280 & merespon \\
\hline 140 & merespon & 290 & merespon \\
\hline 150 & merespon & 300 & merespon \\
\hline
\end{tabular}




\section{$5 \quad$ Kesimpulan}

Berdasarkan hasil uji pada perancangan kontrol Relay dan kecepatan kipas angin Direct Current (DC) dengan sensor suhu LM35 berbasis Internet of Things (IoT) dapat ditarik kesimpulan bahwa pengujian kalibrasi sensor LM35 yang dipakai memiliki persentase error sebesar 1,05\%. Kontrol kecepatan kipas angin DC dengan mode otomatis menghasilkan kenaikan PWM dan RPM ketika suhu semakin panas. Rata-rata kenaikan PWM sebesar 6,3 per kenaikan suhu satu derajat, sedangkan rata-rata kenaikan RPM sebesar 244 per kenaikan satu derajat. Sedangkan kontrol kecepatan kipas angin motor DC pada mode manual bekerja sesuai kecepatan yang diatur dengan PWM dan motor servo bekerja dengan sudut yang sesuai. Selain itu kontrol relay dengan aplikasi Blynk, respon kontrol relay tidak dipengaruhi faktor jarak.

\section{Ucapan Terima Kasih}

Penelitian ini didanai oleh Kementerian Riset dan Teknologi dan Pendidikan Tinggi melalui Hibah Dasar Unggulan Perguruan Tinggi berdasarkan Surat Keputusan Nomor 7/E/KPT/2019 dan Tanggal 19 Februari 2019 dan Perjanjian/Kontrak Nomor 227/SP2H/LT/DRPM/2019.

\section{Daftar Pustaka}

[1] T. Darmanto and H. Krisma, "Implementasi Teknologi IOT Untuk Pengontrolan Peralatan Elektronik Rumah Tangga Berbasis Android," Jurnal Teknik Informatika Universitas Katolik Santo Thomas, vol. 04, no. 01, pp. 1-12, 2019.

[2] R. Khana and U. Usnul, "Rancang Bangun Sistem Keamanan Rumah Berbasis Internet of Things Dengan Platform Android," Jurnal Kajian Teknik Elektro, vol. 03, no. 01, pp. 117, 2014.

[3] H. S. Doshi, M. S. Shah, and U. S. A. Shaikh, "Internet of Things ( IoT ): Integration of Blynk for Domestic Usability," Vishwakarma Journal of Engineering Research, vol. 01, no. 04, pp. 149-157, 2017.

[4] B. A. Prabowo, "Pemodelan Sistem Kontrol Motor DC dengan Temperatur Udara sebagai Pemicu," Jurnal Informatika, Sistem Kendali dan Komputer, vol. 02, no. 01, pp. 39-43, 2010.

[5] S. Sawidin, S. Eksan, and A. A. S. Ramschie, "Android Apllication Design for Smart Home Control," International Journal of Computer Application, vol. 172, no. 04, pp. 25-31, 2017.

[6] A. A. Mustaqim, A. J. Purnama, A. Nuruddin, and H. P. Santoso, "Smart Home System Berbasis IoT," Prosiding Science and Engineering National Seminar 3, pp. 1-7, 2017.

[7] Y. Kashimoto, M. Fujiwara, M. Fujimoto, H. Suwa, Y. Arakawa and K. Yasumoto, "ALPAS: Analog-PIR-Sensor-Based Activity Recognition System in Smarthome," 2017 IEEE 31st International Conference on Advanced Information Networking and Applications (AINA), Taipei, pp. 880-885, 2017.

[8] D. Mohanapriya, R. Reshma, D. Priyadharshini and S. Vinod, "IoT Based Automation of Electricity Consumption in Smarthomes," 2019 IEEE International Conference on 
System, Computation, Automation and Networking (ICSCAN), Pondicherry, India, pp. 1-6, 2019.

[9] I. Parinduri, “Pembelajaran Aplikasi Iot di Android Dengan Software Blynk (Kontrol Led, Relay, dan Suhu)," Seminar Nasional Sains dan Teknologi Informasi, vol. 02, no. 01, pp. 431-435, 2019.

[10]F. Z. Rachman, "Smart Home Berbasis IoT," Prosiding Seminar Nasional Inovasi Teknologi Terapan Politeknik Negeri Balikpapan, vol. 02, no. 01, pp. 396-374, 2017.

[11]B. Bohora, S. Maharjan, and B. R. Shrestha, "IoT Based Smart Home Using Blynk Framework," Zerone Scholar, vol. 01, no. 01, pp. 26-30, 2016.

[12]H. Liang, A. Liu, Y. Chen and C. L. Lee, "Device collaboration in smarthomes as service delivery," Proceedings of SICE Annual Conference 2010, Taipei, pp. 30-34, 2010.

[13]M. S. Nguyen, N. V. Huynh, D. D. Tran and H. T. Ngo, "An Approach of Face Recognition Applied for Smarthome Using System - on - Chip Technology," 2019 International Conference on Advanced Computing and Applications (ACOMP), Nha Trang, Vietnam, pp. 165-170, 2019.

[14]M. Mallick, P. Kodeswaran, S. Sen, R. Kokku and N. Ganguly, "TSFS: An Integrated Approach for Event Segmentation and ADL Detection in IoT Enabled Smarthomes," IEEE Transactions on Mobile Computing, vol. 18, no. 11, pp. 2686-2700, 1 Nov. 2019.

[15]S. Tonage, S. Yemul, R. Jare, and V. Patki, "IoT Based Home Automation System Using NodeMCU ESP8266 Module," International Journal of Advance Research and Development, vol. 03, pp. 332-334, 2018. 